\title{
ANEURYSM OF THE DUCTUS ARTERIOSUS AND UMBILICAL HAEMORRHAGE IN THE NEWBORN
}

\author{
BY \\ BERNARD LENNOX and DERMOD MACCARTHY \\ From the Postgraduate Medical School of London (Hammersmith Hospital)
}

(Received for Publication June 13, 1950)

A recent report of an aneurysm of the ductus arteriosus in a child of 18 days (Pinniger, 1949) has stimulated the following somewhat belated record of a similar case we saw in 1947. The infrequency of reports of this condition would in itself be sufficient justification, but the present case has at least two points of unusual interest: in the first place, the aneurysm was an infective one, and in the second the infection, which was umbilical in origin, had similarly affected the hypogastric vessels which were the source of a fatal haemorrhage.

We propose after describing our case to discuss separately the umbilical haemorrhage and the aneurysm. The literature can best be summarized separately with each. It may be pointed out at once, however, that both these conditions have been the subject of more interest formerly than now, that they seem to have undergone a parallel decline in frequency, and that the reduction of umbilical sepsis has possibly been responsible for that decline.

\section{Case Report}

The mother, aged 37, was uniparous. Wassermann and Kahn tests were negative. Her pregnancy was complicated by essential hypertension, superimposed pre-eclamptic toxaemia, and premature labour at approximately the thirty-fifth week. The puerperium was complicated by pyelitis and a small pulmonary infarct. At labour presentation was vertex, and the second stage lasted for five minutes.

The infant, a boy, weighed $3 \mathrm{lb} .5 \mathrm{oz}$. (1.45 kg.) and was cyanosed at birth. He was kept in an oxygen tent and his colour improved, but cyanosis returned whenever oxygen was discontinued. After 24 hours feeding was started and continued three-hourly thereafter, satisfactory amounts being taken. The stools were normal, and there was no vomiting. On the sixth day the cord separated. On the seventh day the temperature rose to $102 \cdot 8^{-}$F. There was persistent slight cyanosis although the infant was in an oxygen tent. Examination of the heart and lungs showed no abnormality.

On the eighth day the temperature was $102 \cdot 5^{\circ} \mathrm{F}$. and the child looked very grey and ill. Penicillin was started. Feeds were given by tube. On the ninth day there was no change, but on the tenth a slight improvement was noticed. On the eleventh day the infant was found, approximately one hour after the last examination, collapsed and pale with the clothes and blankets soaked with fresh, moderately bright red blood, which had come from the umbilicus. He died a few minutes later. The bleeding point or points were not verified in life.

Necropsy. The body, which was examined five hours after death by Dr. A. M. M. Wilson, was that of a premature male infant weighing $3 \mathrm{lb}$. $(1,360 \mathrm{~g}$.). The skin was pale, without any post-mortem lividity, and was wrinkled and inelastic. The stump of the cord was absent and the umbilicus represented by a small discoloured pit round which there adhered a little fresh blood clot.

The heart was of normal size and configuration. (Its weight was not recorded.) The valves, chambers, and the connexions of the great vessels were all normal. Lying in the anterior mediastinum, in front of and below the left lung root (which was displaced downwards and backwards) below the thymus and above the pericardial reflection, was a red, spherical, cherry-like mass, $10 \mathrm{~mm}$. in diameter, solid to the touch. Dissection showed it to be connected to the upper border of the left pulmonary artery just beyond the saddle by a vessel $5 \mathrm{~mm}$. long and $1.5 \mathrm{~mm}$. in internal diameter, and to the aorta just beyond the slightly marked isthmus by a similar but shorter channel $1 \mathrm{~mm}$. long. The orifices of these two channels into the pulmonary artery and aorta were rounded and open: thrombus could be seen within them but had not extended beyond. The structure obviously. was the ductus arteriosus with a saccular aneurysm arising from its whole circumference near the aortic end. On opening the aneurysm it was seen to be filled with firm, deep red, recent ante-mortem thrombus.

Both hypogastric arteries at and below the umbilicus were thickened, the right more than the left: the right was patent and appeared to have been the source of the haemorrhage. The umbilical vein in the falciform ligament was not thickened and did not appear to be patent.

Other organs showed no changes except pallor. The lungs were normally expanded and no anatomical cause was found for the persistent cyanosis.

Histology. Except for an adenitis of the abdominal lymph nodes, with many polymorphs, and presumably secondary to the umbilical sepsis, lesions were confined to the vascular system. 


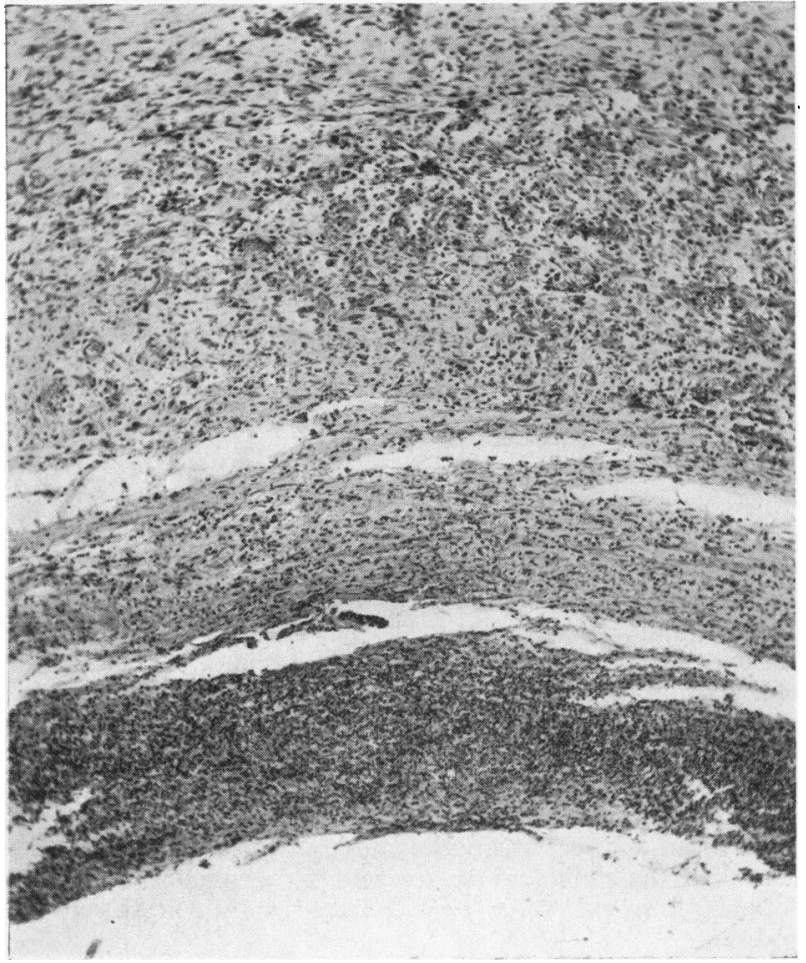

FIG. 1.

Fig. 1.-Wall of aneurysm. H. \& E. $\times 65$. Of the three partially separated layers (artefact) the innermost consists of necrotic tissue densely infiltrated with polymorphs, the others of loose vascular granulation tissue with many polymorphs, and, towards the middle of the outer layer, a few surviving circular muscle fibres.

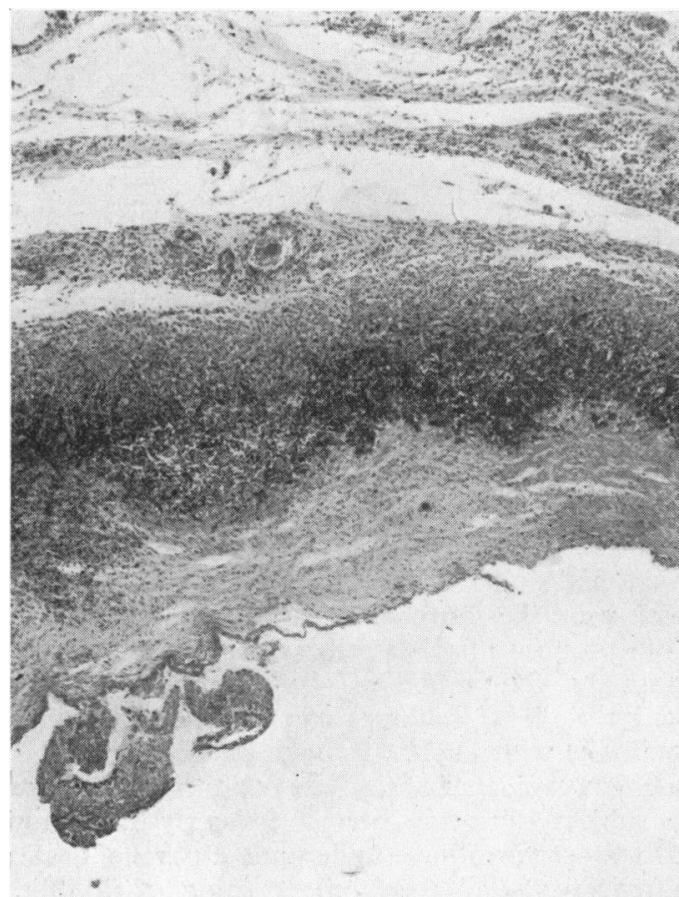

Fig. 2. - Wall of aneurysm, aortic end. H. \& E. $\times 42$. Here the densest inflammatory infiltration is in the innermost zone of the adventitia. The media, especially to the left (nearer the aorta), is well preserved. Towards the right the media is infiltrated, and here some of the recent

Fig. 2

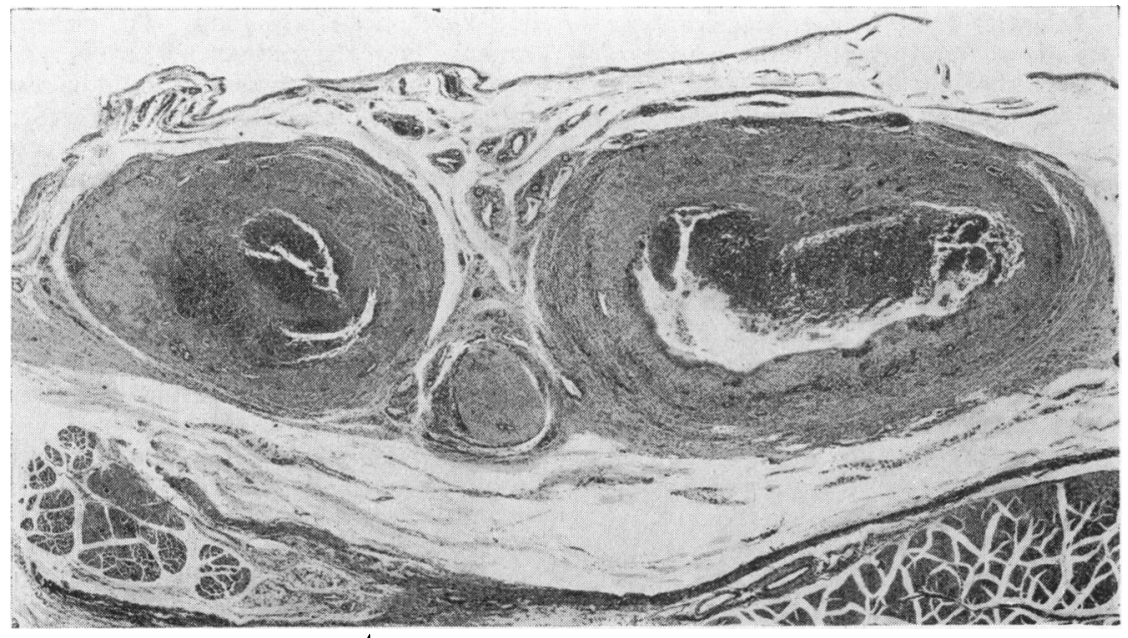

F1G. 3.

FIG. 3.-Hypogastric arteries, near the umbilicus. H. \& E. $\times 15$. The left artery is plugged almost completely by organizing thrombus. The right is dilated, with a lunate lumen round the thrombus. 

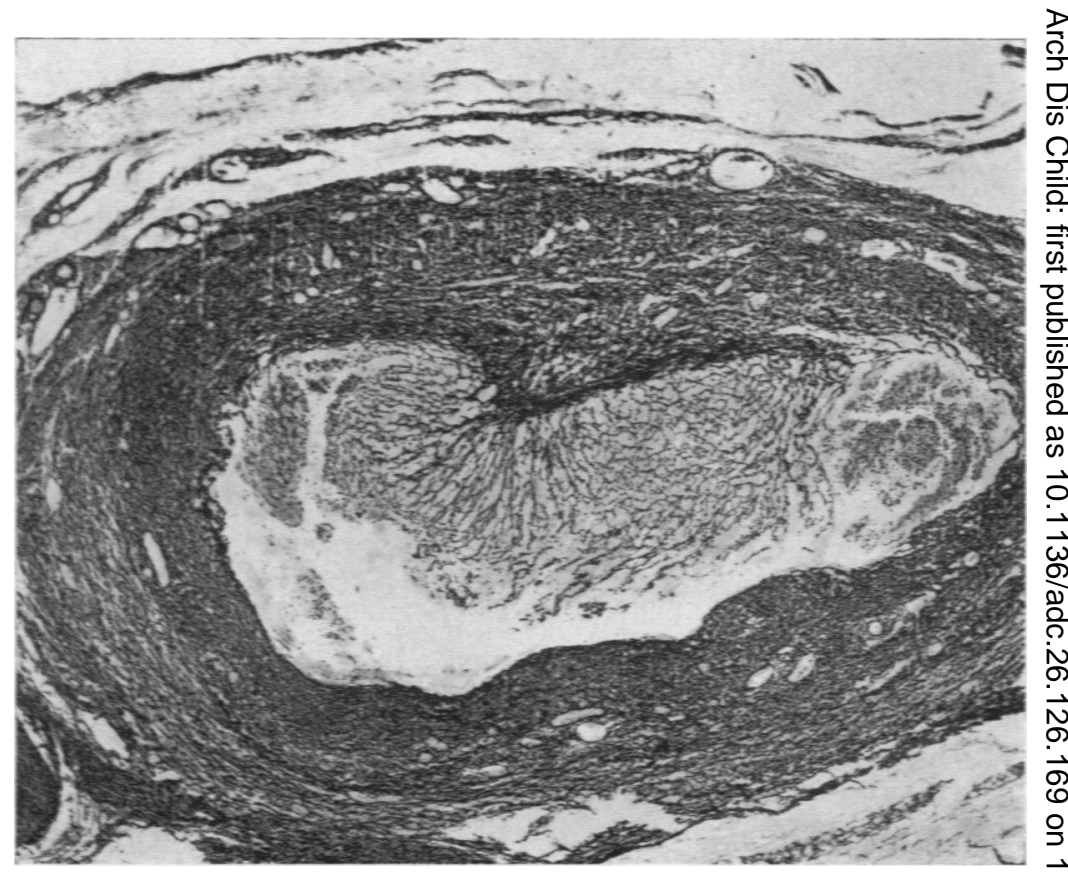

Fus. 4.

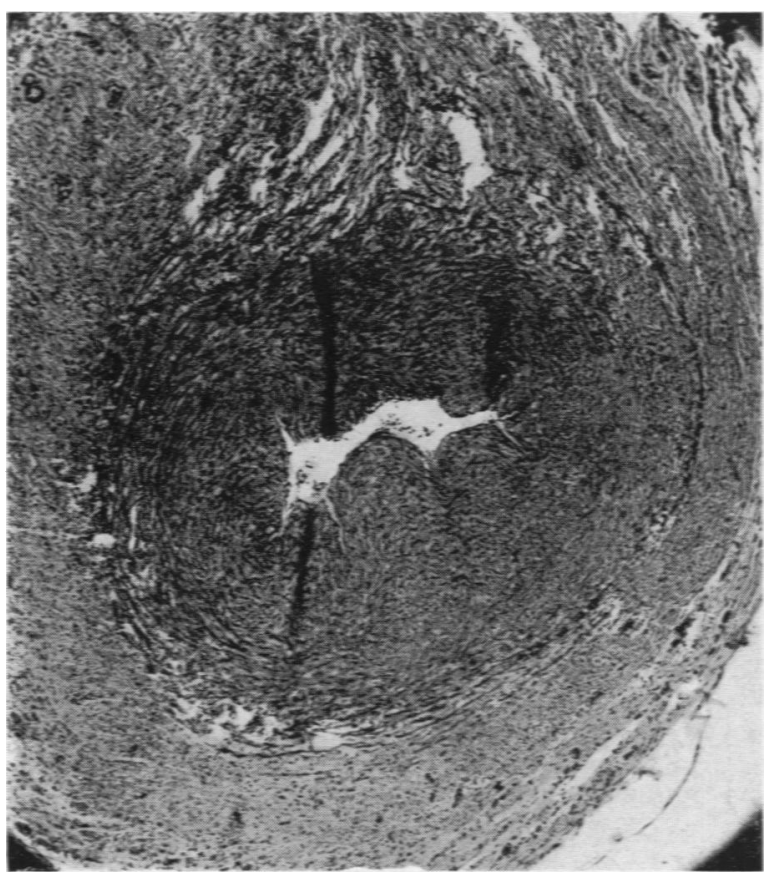

Fig. 5.

Fig. 5.-Right hypogastric artery, at the level of the bladder fundus. Phloxine-tartraxine, $x$ 50. The vessed is normal and patent, though the lumen is not large.

Fig. 6.-Left hypogastric artery at the same level. Phbxinetartrazine, $\times 50$. The vessel wall is densely infiltrated with a polymorph exinate little muscle survivine but the lumen is phued morph exudate litte muscle survivine but the limen is phitiod showed that this clot was more recent than that of Fies. 3 and 4.
FIG. 4.-Right hypoenstric artery, at the same level (reticulin impres nation $x$ 30) showing the oremimtion of the thrombus and the capillaries of the granulation tissue which has replaced most of the media.

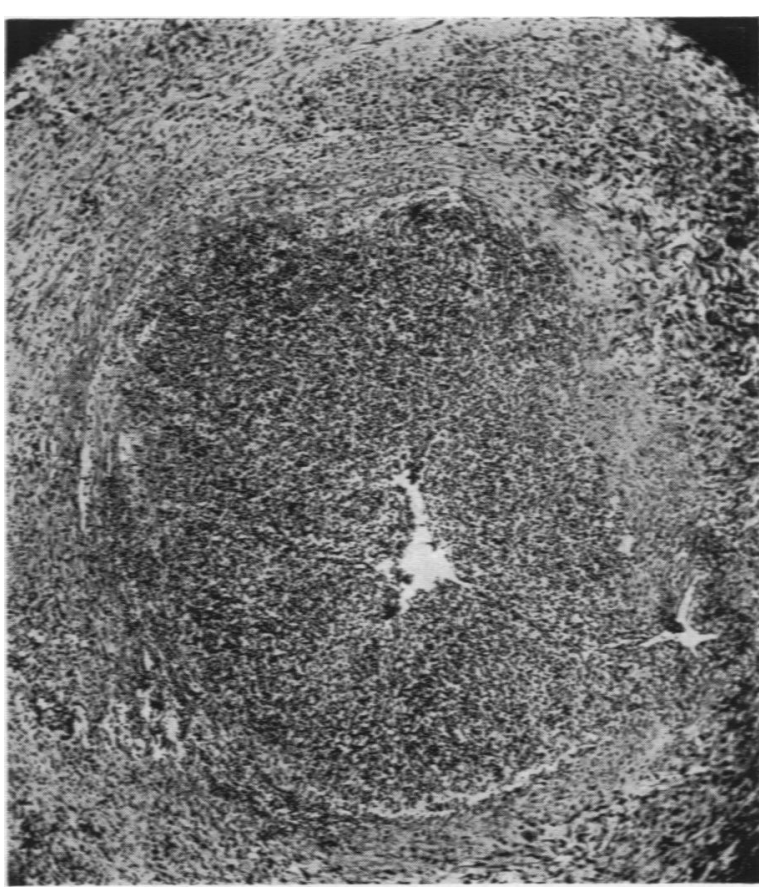

Pa. 6. 
The available histological material of the aneurysm was somewhat fragmentary, but it was clear that in most of its wall the media of the ductus had been destroyed, only a few fibres of its outer compact muscle layer surviving (Fig. 1). The innermost layer of the wall was necrotic and densely infiltrated with pus cells: the recent thrombus which filled the sac had broken away cleanly from this in most places. The outer layer of the aneurysm was largely formed by young granulation tissue. Inflammatory changes had spread widely in the surrounding connective tissue. The undilated part of the ductus near the pulmonary artery had an oedematous wall lightly infiltrated by polymorphs: the intima had been lost but the media was well preserved. The media of the ductus was also well preserved in the part of the aneurysm nearest the aorta (Fig. 2): here the most intense inflammation was found in the adventitia, and the process appeared to be spreading toward the aorta.

Both hypogastric arteries showed acute inflammation with loss, at least in their upper portions, of nearly all the muscle in their walls. The left was almost completely obstructed by organized septic thrombus: in the right a similar thrombus of about the same diameter was present but dilatation of the vessel had resulted in the presence of a large crescentic lumen (Figs. 3 and 4). At the level of the bladder fundus the left artery was still inflamed (Fig. 6), and almost occluded by thrombus which a reticulin impregnation showed to be much younger than that nearer the umbilicus: the right artery was uninflamed and patent (Fig. 5). The umbilical vein near the umbilicus was acutely inflamed and not obliterated, but it was collapsed and compressed by surrounding granulation tissue and did not seem a likely source of haemorrhage.

No organisms were recognized in any of these lesions, but in view of the recent treatment with penicillin this was probably not a significant finding.

\section{Discussion}

Umbilical Haemorrhage in the Newborn. Late haemorrhage from the umbilicus in the newborn is a well known though somewhat rare occurrence. It appears to be rarer now than it was 10 to 20 years ago when umbilical sepsis, which undoubtedly may play a part in its causation, was common. Since the discovery of vitamin $K$, concentration on the relation of prothrombin deficiency to haemorrhagic manifestations in the newborn has resulted in the frequent acceptance of umbilical haemorrhage as a manifestation of haemorrhagic disease of the newborn ' without due reference to any local pathological process or anatomical fault which might be the cause: Clifford (1942), however, emphasizes neonatal asphyxia as one important factor in initiating the primary break in the vascular tree. Opportunities for studying this question are rare, Renther (1927) giving the incidence of umbilical haemorrhage as four in approximately 20,000 births. And opportunities are becoming rarer still as more of these babies are saved by timely transfusion. Reports in the literature also are few and far between, and we have been unable to find any giving a sufficiently detailed description of the state of the umbilical vessels for a comparison with our own case.

In our case there is no question that one of the umbilical arteries was the source of the bleeding, and discussion of the cause may reasonably be confined to two possibilities $(a)$ infection, and (b) failure of the normal physiological mechanism maintaining the closure of these arteries.

(a) INFECTION. Von Reuss (1920) sums up much of what was known about umbilical infection at that time, and describes "umbilical arteritis ${ }^{\circ}$ as due to the spread of infection to the thin core of thrombus in the artery. Suppuration usually does not extend beyond the wall of the vessel; pus may exude from the navel or be confined to parts of the artery further from it. Haemorrhage is mentioned as an occasional complication, and according to von Reuss must be regarded as a sign of sepsis whether this is obvious or not. Surprisingly, in spite of this danger, probing of the vessels for the release of pus is the treatment recommended and appears to be safe, constriction of the caudal end of the artery and integrity of the thrombus there presumably being sufficient to keep the vessel closed. Obviously the spread of the infection down the thrombus to the larger trunks may give rise to septicaemia and any of its clinical manifestations. Umbilical periarteritis, which is said to be commoner than arteritis, carries an even greater risk of general spread. Either condition may be occult and give rise to chronic septicaemia. The subject of omphalitis was reviewed by Chamberlain (1936), but haemorrhage is not mentioned as a complication.

Apart from sepsis, the only form of infection reported as a cause of umbilical haemorrhage is congenital syphilis, in which it appears to be relatively frequent (Hutinel, 1904; von Reuss. 1920; Voron and Pigeaud, 1927: Manouélian. 1934: Hallez and Garnier, 1940: Snelling, 1942). There is usually ulceration at the navel. We have been able to find only two accounts of the histology of this condition, and they do not tally: Hutinel describes endarteritis and periarteritis of the umbilical arteries, whereas Manouélian describes a chancre-like lesion, full of spirochaetes, involving the umbilical vein which it had perforated: syphilitic disease of the liver may have raised the pressure within the vein. In our case the routine antenatal Wassermann test on the mother was negative. The infant's blood was not tested, but the histology of the affected vessels and of the other organs did not suggest syphilitic disease. 
(b) Failure of Physiological Mechanisms. The experiments of Cattaneo (1935) in the sheep showed that a rise in oxygen in the foetal blood results in closure of the umbilical arteries. It is probable that the mechanism is a local one, for in the ductus an apparently similar mechanism has been shown in the guinea-pig to be independent of any external nervous connexions (Kennedy and Clark, 1942). Nerves have been demonstrated fairly conclusively in the ductus (Kennedy and Clark, 1941) and in the hypogastric-but not umbilical-arteries (Spivack, 1943) and may be involved in this local reflex. It seems therefore reasonable to suppose that a persistent low arterial oxygen tension after birth may interfere with the normal closure of the arteries at the umbilicus.

In the present case the histological evidence for sepsis as the major cause of the haemorrhage was strong. A spreading septic thrombosis had occurred in the two vessels. One appeared to have remained safely occluded, the other to have reopened and bled. In the reopening two factors are involved, a breakdown of the organized thrombus (Fig. 4) and, probably more important, weakening of its wall by the destruction of its muscular elements. Both of these processes may be ascribed to the infecting organism. Clear though this sequence is, it is nevertheless worth noting that this infant was cyanosed at birth and remained in a state of intermittent oxygen want throughout its short life of 11 days. It is not therefore impossible that the mechanism of closure of both umbilical artery and ductus was in some way imperfect-perhaps involving the presence of an abnormal amount of thrombus-and allowed the later infective complications to appear more easily.

Cases in the literature in which sepsis can be excluded as a cause of haemorrhage are not numerous. They include the few reported instances of severe bleeding from the umbilicus in several infants born to the same parents (Taylor, 1893, in three infants; Laurentie, 1921, in five infants; Baron, 1929, in three infants). Two other cases, both fully described, are worth mentioning. Trillat, Bertoye, and Doucet-Bon (1938) reported a case with fatal haemorrhage into the subperitoneal tissues causing a huge haematoma: the umbilical arteries were said to be normal and no evidence of sepsis or syphilis was found. In Schultze's case (1927), which recovered, the explanation offered was a detachment of thrombi from the open end of the arteries owing to their adherence to a mass of inspissated cord powder and exudate in the navel.

Aneurysm of the Ductus. Pinniger's is the only aneurysm of the ductus in infancy to be reported in the English literature, and the only American cases are those of Dry (1917) and Gross (1945, Case V). There have, however, been numerous reports from the continent; the most recent is that of Scheef (1939), but many are of a considerable age. Details of most of them will be found in the papers of Thoma (1889), Roeder (1900), Bronson and Sutherland (1918), and Scheef. The earliest report we have been able to find is that of Martin (1827), but Thore (1850) records earlier reports by Baron (undated) and Billard (1826). Thore himself, in something over 1,000 necropsies at the Hôpital des Enfants Trouvés found eight ductus aneurysms. His descriptions are clear and unequivocal, and his report must be accepted as a fair estimate of the true frequency of the condition in his day. Kaufmann's case (1929) must be mentioned for its similarity to the present case. Ductus aneurysms in later ages have been reported by Thoma (1890), Hebb (1893), Thomson and Drummond (1900. Case I), Hutchison (1922), Altschule (1937), and Graham (1940, two cases): they form a curious and very interesting group, probably various in origin, and of little relevance here, for few of them (Hutchison's, in a girl of 6, is the only really probable one) seem to have arisen as a simple survival into later life of an aneurysm of the infantile type.

The sequence of events in the present case seems reasonably clear. Umbilical sepsis was the first event, followed by a spreading septic thrombosis in the two hypogastric arteries. Meanwhile, the same organisms circulating in the blood settled in the ductus, its wall was weakened in exactly the same way as that of the hypogastric artery, and the aneurysm resulted. The surprising thing is, not that this should occur, but that it should occur so rarely. The ductus arteriosus is for several weeks, until its total occlusion, a diverticulum of the circulation with degenerative changes occurring in the wall (Barnard, 1939), sometimes (Blumenthal, 1947) amounting to frank necrosis, and some sort of colonization might be expected to be extremely common. Yet it is very infrequent. The ductus is at first closed only by spasm (Barclay, Barcroft, Barron, and Franklin, 1939; Kennedy and Clark, 1941), but the injection experiments of the latter authors (1942) on the foetal guinea-pig added to the present considerations indicate that the spasm of the ductus is sufficient to exclude it completely from the general circulation in all ordinary circumstances. It is simplest to assume that in the present case the ductus was already abnormal, either patent, or closed by aseptic thrombosis. Thrombosis of the ductus (Bettinger, 1932; Gross, 1945) is rarely recognized, but as it is hardly recognizable unless it draws attention to itself by emitting emboli and 
causing, for example, peripheral gangrene or infarcts, it may be less uncommon than is generally supposed. Certainly it would form an ideal nidus for the colonization of circulating bacteria, and it seems to us much the most likely basis of the infection in our case.

It is probable that the mechanism in the reported cases is not always the same. Kaufmann's case may well be the same as ours, but no associated infection is reported in Gross's case (nor does it seem probable in Thore's series, though in the absence of histology this must remain uncertain) and in Pinniger's case, though there was plenty of opportunity for infection, the histology (in spite of some superficial resemblance of his Fig. 3 to our Fig. 4) is not that of a mycotic aneurysm. It is possible, of course, that the aneurysm in our case began as one of the aseptic type (it is interesting to note that its site, rather nearer the aorta than the pulmonary artery, was that of every one of Thore's series), but we find it difficult to doubt that the septic destruction of the vessel wall has had a major part in producing the dilatation.

There seems to be no evidence as to the ultimate fate of these aneurysms. Most patients have died of intercurrent disease. Scheef's is the only case of rupture we have found, yet persistence of the aneurysm into adult life is excessively rare if it occurs at all. The answer is probably to be found in the thrombus which fills most of these aneurysms. It must often organize, the resultant fibrosis obliterating the ductus. If it recanalizes how may the result be distinguished in time from any ordinary patent ductus?

One last bare possibility remains, that the hypogastric arteries and the ductus, which are not dissimilar in structure and suffer simultaneously a similar fate, possess in common some disorder which has produced the changes in both seen in this case. No such congenital arteritis is known, nor does any mechanism of its origin present itself to our imagination, and we prefer to consider the process a simple bacterial infection.

\section{Summary}

A premature baby died of sudden umbilical haemorrhage on the eleventh day. At necropsy a $10 \mathrm{~mm}$. aneurysm of the ductus arteriosus was found. A septic arteritis of the hypogastric arteries was present, and was the cause of the umbilical haemorrhage: a similar change was present in the wall of the ductus aneurysm and was attributed to septicaemic spread of the same infection.

Our thanks are due to Professor A. A. Moncrieff and Dr. C. V. Harrison for their interest, to Mr. J. Griffin for the sections, and to Mr. E. V. Willmott for the photomicrographs.

\section{REFERENCES}

Altschule, M. D. (1937). Amer. Heart J., 14, 113.

Barclay, A. E., Barcroft, J., Barron, D. H., and Franklin, K. J. (1939). Brit. J. Radiol., 12, 505.

Barnard, W. G. (1939). St. Thom. Hosp. Rep., 2 ser., 4, 72.

Baron, P. (1929). Gynéc. et Obstét., 20, 757.

Bettinger, H. (1932). Zbl. allg. Path. path. Anat., 54, 289.

Billard (1926) quoted by Thore.

Blumenthal, L. S. (1947). Arch. Path., 44, 372.

Bronson, E., and Sutherland, G. A. (1918). Brit. J. Child. Dis., 15, 241.

Cattaneo, L. (1935). Ann. Ostet. Ginec., 57, 319.

Chamberlain, J. W. (1936). J. Pediat., 9, 215.

Clifford, S. H. (1942). Ibid., 20, 650.

Dry, D. M. (1917). Proc. path. Soc. Philadelphia, 19, 49.

Graham, E. A. (1940). Arch. Surg., Chicago, 41, 324.

Gross, R. E. (1945). Amer. J. Dis. Child., 70, 61.

Hallez, M. G. L., and Garnier (1940). Bull. Soc. Pédiat. Paris, 37, 624.

Hebb, R. G. (1893). Trans. path. Soc. London, 44, 45.

Hutchison, R. (1922). Brit. J. Child. Dis., 19, 85.

Hutinel, V. (1904). Abstracted from La Syphilis in Arch. Kinderheilk., 38, 298.

Kaufmann, E. (1929). 'Pathology' trans. by Reimann, S. P. (Philadelphia and London), vol. I, p. 96.

Kennedy, J. A., and Clark, S. L. (1941). Anat. Rec., $79,349$.

- 1 (1942). Amer. J. Physiol., 136, 140.

Manouélian, Y. (1934). C. R. Acad. Sci., Paris, 199, 1690.

Laurentie (1921). Bull. Soc. Obstét. Gynéc. Paris, 10, 777.

Martin (1827). Bull. Soc. anat. Paris, 2, 17. 2nd ed. Paris, 1944.

Pinniger, J. L. (1949). J. Path. Bact., 61, 458.

Renther (1927). Bull. Soc. Obstét. Gynéc., Paris, 16, 81.

Reuss, A. R. von (1920). 'The Diseases of the Newborn.' London.

Roeder, H. (1900). Arch. Kinderheilk., 30, 157.

Scheef, S. (1939). Arch. Kinderheilk., 117, 234.

Schultze, G. K. F. (1927). Z. Geburtsh. Gynäk., 91, 171.

Snelling, C. E. (1942). J. Pediat., $20,644$.

Spivack, M. (1943). Anat. Rec., 85, 85.

Taylor, J. (1893). Bristol med-chir. J., 11, 237.

Thoma, R. (1889). Dtsch. med. Wschr., 15, 340.

(1890). Virchows'Arch., 122, 535.

Thomson, J., and Drummond, W. B. (1900). Edinb. Hosp. Rep., 6, 57.

Thore (fils) (1850). Arch. gén. Med., 4 sér. 23, 30.

Trillat, Bertoye and Doucet-Bon (1938). Bull. Soc. Obstét. Gynéc., Paris, 27, 288.

Voron and Pigeaud (1927). Ibid., 16, 80. 